\title{
Modulation of the $\boldsymbol{N}$-methyl-D-aspartate channel by extracellular $\mathrm{H}^{+}$
}

\author{
Cha-Min Tang*, Marc Dichter*, and Martin Morad \\ Department of Physiology, University of Pennsylvania, Philadelphia, PA 19104-6085
}

Communicated by E. Costa, March 15, 1990

\begin{abstract}
The influence of external $\left[\mathrm{H}^{+}\right]$on whole-cell and single-channel currents activated by glutamate agonists was studied in rat hippocampal neurons. In the $\mathrm{pH}$ range between 6.6 and 8.0, changes in external $\left[\mathrm{H}^{+}\right]$had negligible influence on the amplitude and kinetics of the monovalent ion-carrying currents activated by the agonists quisqualate and kainate. The divalent ion-carrying $\boldsymbol{N}$-methyl-D-aspartate (NMDA)-activated current, on the other hand, was strongly modulated by extracellular $\left[\mathrm{H}^{+}\right]$. Increased external $\left[\mathrm{H}^{+}\right]$suppressed, whereas decreased external $\left[\mathrm{H}^{+}\right]$enhanced, the NMDA-activated current. Changes in internal $\left[\mathrm{H}^{+}\right]$had little or no effect on the NMDA-activated current. Modulation of the NMDA-activated current resulted primarily from changes in the number of channel openings. Neither the unitary conductance nor the individual open dwell-times were significantly affected. These results suggest that the protonation site is on the external aspect of the channel and is far removed from the channel permeation pathway. Because interactions between $\mathrm{H}^{+}, \mathrm{NMDA}$, and glycine in activating the current were predominantly noncompetitive, our results suggest that the modulatory effect of $\mathrm{H}^{+}$was not associated with changes in receptor-agonist affinities. These results suggest that modulation of the NMDA-receptor channel by $\left[\mathrm{H}^{+}\right]$may be an intrinsic protective mechanism by which calcium influx into neurons is regulated, particularly in hypoxic/ischemic conditions.
\end{abstract}

Glutamate is believed to be the neurotransmitter responsible for excitatory synaptic transmission within much of the mammalian central nervous system $(1,2)$. The $N$-methyl-Dasparate (NMDA) channel is one of several subsets of neuronal ionic channels activated by glutamate. The NMDA channel is characterized by (i) high permeability to $\mathrm{Ca}^{2+}(3)$, (ii) marked potentiation by glycine (4), and (iii) voltage dependence in the presence of external $\mathrm{Mg}^{2+}(5,6)$. Activation of the NMDA channel is required for the induction of long-term potentiation (7), one mechanism thought to be involved in learning and memory. Excessive activation may contribute to the generation of seizures (8). Calcium entry through NMDA channels has also been postulated to contribute to the irreversible neuronal lesions associated with hypoxic/ischemic injury (9).

Because $\left[\mathrm{H}^{+}\right]$in the extracellular space surrounding central nervous system neurons $\left(\left[\mathrm{H}^{+}\right]_{0}\right)$ changes with repetitive activation and under pathologic conditions (10), we examined how changes in $\left[\mathrm{H}^{+}\right]_{0}$ influence behavior of the NMDA receptor-channel complex. In preliminary reports (11), we noted that although the monovalent ion-transporting quisqualate and kainate channels were relatively insensitive to $\left[\mathrm{H}^{+}\right]_{\mathrm{o}}$, the divalent ion-permeant NMDA channels were highly regulated by $\left[\mathrm{H}^{+}\right]_{0}$. In this study we characterize the $\mathrm{pH}$ sensitivity of the NMDA-activated current and investigate further the site and mechanism by which $\mathrm{H}^{+}$modulates the NMDA receptor-channel complex.

The publication costs of this article were defrayed in part by page charge payment. This article must therefore be hereby marked "advertisement" in accordance with 18 U.S.C. $\$ 1734$ solely to indicate this fact.

\section{METHODS}

Rat hippocampal neurons obtained from 21-day embryos and maintained in dissociated cell culture for 2 to 4 weeks were used in these studies. The hippocampus was removed, incubated in trypsin $\left(0.027 \%\right.$; Sigma) in $\mathrm{Ca}^{2+}$ - and $\mathrm{Mg}^{2+}$-free medium, tritiated, and filtered to remove clumps. Neurons were plated on polylysine-coated coverslips at $6 \times 10^{5}$ cells per 35-mm tissue-culture dish. Cells were maintained in Dulbecco's minimum essential medium/5\% Ham's F-12 medium containing glutamine, $5 \%$ Hyclone calf serum, penicillin at 50 units, and $0.05 \mathrm{mg}$ of streptomycin per $\mathrm{ml}$. The medium was changed three times per week. Cytosine arabinoside $\left(10^{-5} \mathrm{M}\right)$ was added for $24 \mathrm{hr}$ at $\approx 1$ week to suppress background cell overgrowth

During electrophysiological experiments, cells were bathed in a solution containing $150 \mathrm{mM} \mathrm{NaCl}, 3 \mathrm{mM} \mathrm{KCl}, 2$ $\mathrm{mM} \mathrm{CaCl} 2,3 \mu \mathrm{M}$ tetrodotoxin, and $10 \mathrm{mM}$ Hepes. Ten millimolar Pipes was used when solutions were buffered below $\mathrm{pH}$ 7.0. One millimolar $\mathrm{MgCl}_{2}$ was added to the external solution in experiments where quisqualate, kainate, and $\gamma$-aminobutyric acid were used. The internal pipette solution, in general, was $140 \mathrm{mM} \mathrm{CsCl} / 10 \mathrm{mM}$ bis(2aminophenoxy)ethane- $N, N, N^{\prime}, N^{\prime}$-tetraacetate (BAPTA)/1 $\mathrm{mM} \mathrm{MgCl} / 1 \mathrm{mM} \mathrm{MgATP} / 10 \mathrm{mM}$ Hepes, titrated to $\mathrm{pH} 7.3$ with $\mathrm{NaOH}$. External solutions were changed by using a rapid "concentration clamp" system. This perfusion system was constructed by connecting multiple solutions via thin tubings to the two sides of a theta glass tubing pulled to a $200-\mu \mathrm{m}$ opening. The tip was shaped such that solutions from the two sides of the theta tubing would flow over the same area of the chamber. Rapid solution changes were made by electronically controlling the flow of solutions on the two sides of the theta tubing.

Membrane currents were measured under voltage-clamp conditions in either whole-cell or outside-out configuration of the patch-clamp technique (12). Recordings of single-channel currents were sampled at $5 \mathrm{kHz}$ and stored after filtering at $1 \mathrm{kHz}$ with an 8-pole low-pass Bessel filter. Analysis of the data for determining the amplitude and dwell-time histograms used version 5.5 of PCLAMP (Axon Instruments, Burlingame, CA). For this analysis overlapping channel openings and events lasting $<0.5 \mathrm{msec}$ were rejected.

\section{RESULTS}

Effects of Changes in pH on Whole-Cell Current. Changes in $\left[\mathrm{H}^{+}\right]_{0}$ altered the currents activated by the selective glutamate agonists and $\gamma$-aminobutyric acid in distinctly different ways. Fig. 1 shows that changes in $\left[\mathrm{H}^{+}\right]_{\mathrm{o}}$ in the $\mathrm{pH}$ range between 6.6 and 8.0 had no appreciable effect on the quisqualate- and kainate-activated currents. On the other hand, alkalization enhanced, whereas acidification suppressed, the NMDA-activated current in a rapid and reversible manner. The modulatory effect of $\mathrm{H}^{+}$was not restricted

Abbreviation: $\left[\mathrm{H}^{+}\right]_{0}$, external $\mathrm{H}^{+}$concentration.

*Present address: Department of Neurology, Graduate Hospital, University of Pennsylvania, Philadelphia, PA 19146. 
pH 7.3 8.0

7.3

6.6

NMDA<smiles>CC[C@H]1CC[C@@H](CC)[C@H]1C</smiles><smiles>CCC1CC1</smiles>

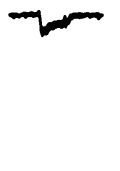<smiles>CCCCCCCC</smiles>

QUIS<smiles>CCCCC</smiles><smiles>CCCCC</smiles><smiles>CCCCC</smiles><smiles>CCCC</smiles><smiles>CCCC</smiles>

KAIN
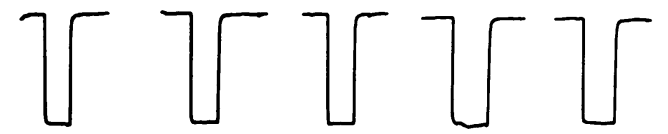

GABA
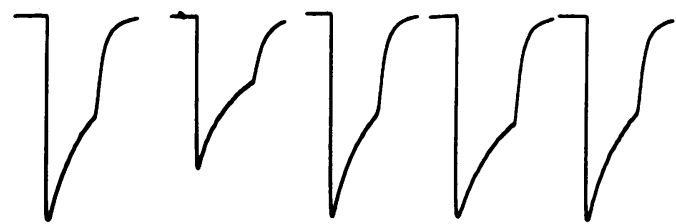

FIG. 1. Changes in external $\mathrm{pH}$ affect currents activated by selective glutamate agonists and $\gamma$-aminobutyric acid (GABA) differently. Hippocampal neurons were patch clamped, and whole-cell currents were measured as agonists were applied in step pulses at various $\mathrm{pH}$ values. The time interval between each step application was $\approx 10-15 \mathrm{sec}$. $\mathrm{pH}$ was changed in the order indicated. When agonist was not being applied, control solution was applied at the same flow rate. Concentration for all four agonists was $100 \mu \mathrm{M}$. Calibration bar represents $0.5 \mathrm{nA}$ for NMDA traces and $2.5 \mathrm{nA}$ for the other traces. Holding potential was $-80 \mathrm{mV}$. QUIS, quisqualate; KAIN, kainate.

to the transient component of NMDA-activated currents, as suggested from an earlier study (13). Addition of $\mathrm{Mg}^{2+}$ to the external solution did not interfere with the modulatory effect of $\mathrm{H}^{+}$(data not shown). The suppressive effect of alkalosis on the $\gamma$-aminobutyric acid-activated current is shown in Fig. 1 to further illustrate that $\mathrm{H}^{+}$exerts differential actions on different receptor channels.

Fig. $2 A$ summarizes the $\mathrm{pH}$ dependence of the NMDA current measured at $1 \mathrm{sec}$ after step application of NMDA in 26 neurons. The data were fitted to a sigmoidal curve with a pKa of 6.9 and a Hill coefficient of 1.2. The proximity of the pKa of NMDA modulation to physiological $\mathrm{pH}$ makes the channel highly sensitive to relatively small perturbations in $\left[\mathrm{H}^{+}\right]_{\mathrm{o}}$ at physiological $\mathrm{pH}$.

To study whether the modulatory action of $\mathrm{H}^{+}$is mediated through changes in receptor affinity for NMDA and glycine, experiments were done to examine whether $\mathrm{H}^{+}$interacted with the NMDA and glycine dose-response relationship in a competitive or a non-competitive manner. Fig. $2 B$ shows that the degree to which the NMDA current is modulated by changes in $\left[\mathrm{H}^{+}\right]_{\mathrm{o}}$ was relatively independent of the NMDA concentration, suggesting a noncompetitive interaction between $\mathrm{H}^{+}$and NMDA. If the primary effect of $\mathrm{H}^{+}$were the modulation of NMDA binding, then a significant leftward shift of the dose-response curve would have been expected at $\mathrm{pH} 8.0$ as compared with $\mathrm{pH}$ 6.6, and the currents would have approached each other with increased NMDA concentration. Our results, therefore, suggest that $\mathrm{H}^{+}$does not interfere significantly with NMDA binding. Furthermore, we found that $\mathrm{H}^{+}$similarly modulated the current activated by a selective endogenous NMDA channel agonist, aspartate.

Fig. $2 C$ illustrates that $\left[\mathrm{H}^{+}\right]_{\mathrm{o}}$ also alters the glycine modulation of the NMDA current. $\mathrm{H}^{+}$and glycine appear to interact primarily in a noncompetitive manner. In a separate set of experiments, increasing the glycine concentration even to $500 \mu \mathrm{M}$ failed to converge the current amplitudes of different $\mathrm{pH}$ values. At low glycine concentrations, however, a component of competitive interaction is suggested by a shift in the $K_{\mathrm{d}}$ of glycine modulation (from $290 \mathrm{nM}$ at pH 7.3 to 900 $\mathrm{nM}$ at $\mathrm{pH}$ 6.3; Fig. 2). This finding suggests that although the dominant modulatory action of $\mathrm{H}^{+}$is not mediated by changes in glycine-binding affinity, some modulation may result from such changes.

Glycine has been suggested to modulate the NMDAactivated current by changing the desensitization rate of the
A

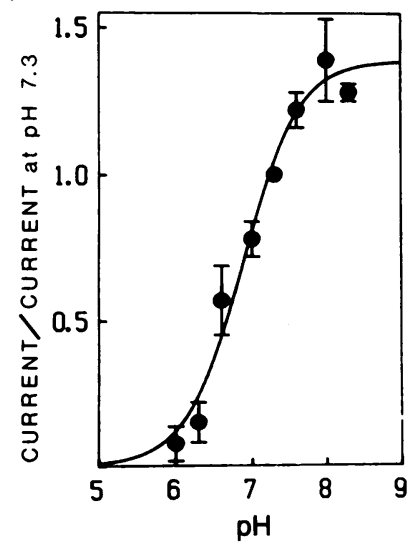

B

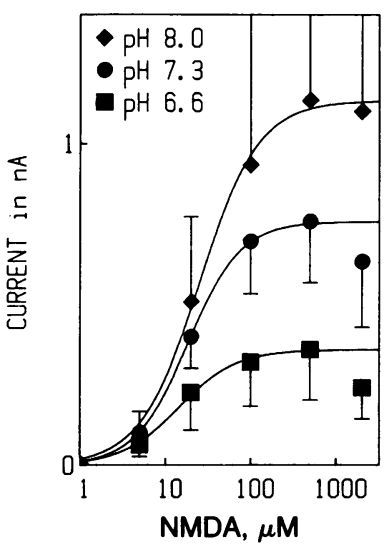

C

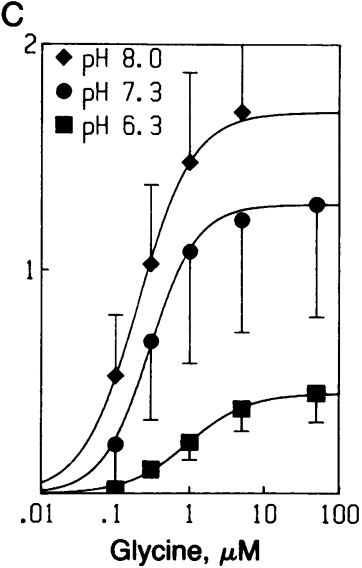

Fig. 2. Interaction between $\mathrm{H}^{+}, \mathrm{NMDA}$, and glycine. $(A) \mathrm{pH}$ dependence of the NMDA-activated current with activating NMDA concentration held at $100 \mu \mathrm{M}$ and glycine concentration maintained at $1 \mu \mathrm{M}$. Currents from 26 neurons were measured each at three different $\mathrm{pH}$ values $1 \mathrm{sec}$ after step application of NMDA. Currents at each $\mathrm{pH}$ were normalized to that measured at $\mathrm{pH}$ 7.3. Holding potential was -80 $\mathrm{mV}$. (B) Influence of external $\mathrm{pH}$ on NMDA dose response. For each neuron the $\mathrm{pH}$ and glycine concentrations $(1 \mu \mathrm{M})$ remained constant while the activating NMDA concentrations were changed $(n=6$ for $\mathrm{pH} 6.6,7$ for $\mathrm{pH} 7.3$, and 11 for $\mathrm{pH}$ 8.0). Current amplitude was measured at $1.5 \mathrm{sec}$ from step change in NMDA concentration for both $B$ and $C$. Current amplitudes were not normalized. Similar-appearing cells grown in the same culture dish were used. Holding potentials were $-\mathbf{8 0} \mathrm{mV}$. (C) Influence of external $\mathrm{pH}$ on the glycine-modulation dose response. For each neuron, $\mathrm{pH}$ and NMDA concentration $(100 \mu \mathrm{M})$ remained constant, as glycine concentrations were changed $(n=7$ for pH $6.3,8$ for $\mathrm{pH}$ 7.3, and 8 for $\mathrm{pH} \mathrm{8.0)}$. 
$\mathrm{pH} 7.3$ 6.3 8.0 7.3
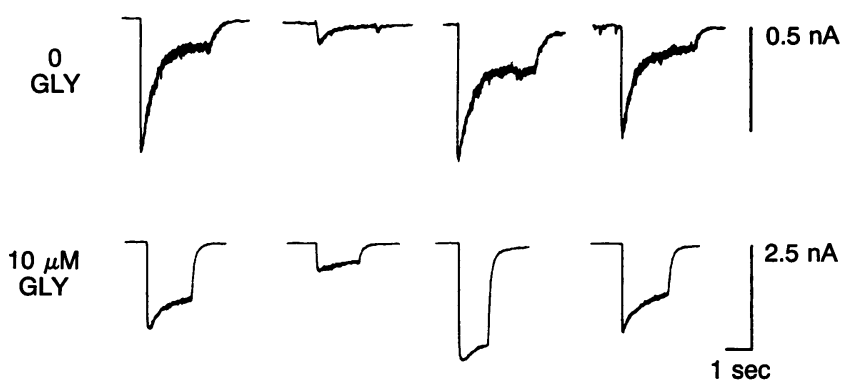

FIG. 3. Effect of glycine (GLY) on modulation by external $\mathrm{H}^{+}$. Without added glycine, the NMDA-evoked current was nearly completely suppressed at pH 6.3; with $10 \mu \mathrm{M}$ of glycine, current suppression was less. Holding potential was $-80 \mathrm{mV}$. NMDA concentration was $100 \mu \mathrm{M}$.

NMDA response (14). Fig. 3 shows that $\left[\mathrm{H}^{+}\right]_{0}$ modulates the peak and late currents activated by NMDA similarly. We found no consistent change in the rate of decay of current at different $\mathrm{pH}$ values. Furthermore, consistent with the findings of Fig. $2 C$, modulation of the NMDA current by $\mathrm{H}^{+}$was more pronounced at lower glycine concentrations.

Possible Site of Action of $\mathbf{H}^{+}$. To locate the protonation site, neurons were dialyzed with pipette solutions buffered either at $\mathrm{pH} 6.3$ or 8.0. The NMDA-activated currents under these two conditions did not differ significantly $(n=8$ for each $\mathrm{pH})$. If the regulatory site were located on the cytoplasmic side of the channel, the current would have changed, at least, by as much as the change in extracellular pH (e.g., a 10-fold difference, Figs. 1 and 2).

A protonation site within the channel pore close to the $\mathrm{Mg}^{2+}$ binding site was also considered. Such a site would necessarily sense changes in the membrane electric field and impose a voltage dependence on the $\mathrm{H}^{+}$-induced effects. Fig. 4 shows that elevation of $\left[\mathrm{H}^{+}\right]_{0}$ suppresses the NMDAactivated current similarly at -40 and $+40 \mathrm{mV}$, providing little support for a voltage-dependent response. These re-
pH 7.3

6.3
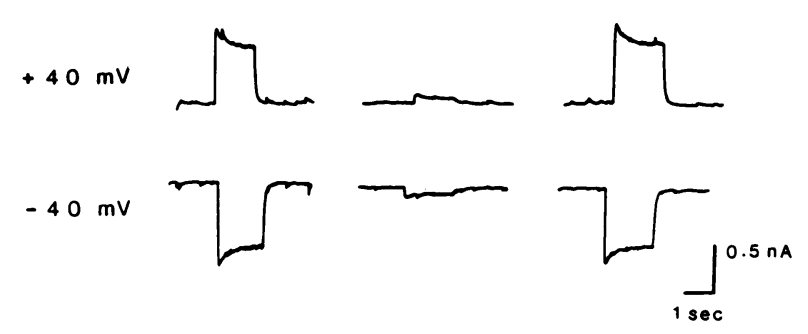

FIG. 4. Voltage independence of modulation by $\mathrm{H}^{+}$. Degree of current suppression at $\mathrm{pH} 6.3$ does not significantly differ between $-40 \mathrm{mV}$ and $+40 \mathrm{mV}$. NMDA concentration was $100 \mu \mathrm{M}$.

sults, therefore, suggest that the protonation site is on the external aspect of the NMDA receptor-channel complex.

Evidence from Unitary Events. The modulation of NMDAactivated current was also seen in excised outside-out membrane patches, suggesting that modulation occurs directly on the NMDA receptor-channel complex and does not require an intact cellular structure or intracellular second messengers (Fig. 5A). The dominant action of $\mathrm{H}^{+}$on the NMDA channel is to modulate the number of channel openings. Unitary NMDA channel events may consist of openings into either a single high conductance or a number of subconductance states (15). Recordings from an excised membrane patch containing NMDA channels show prominent transitions between a number of subconductance states (Fig. 5). There were no qualitative differences in the $\mathrm{pH}$ responses between those channels that showed frequent transitions and those that remained primarily in one high-conductance state.

Unitary current recordings were analyzed to determine whether the protonation site was close to the permeation pathway of the channel. Fig. $5 B$ and $C$ summarize the unitary conductances and open dwell-time data for the patch of Fig. $5 A$. The data indicate that the unitary channel conductances do not change significantly with $\mathrm{pH}$ alteration. Further, the decrease in the number of channel openings appeared most marked for the highest conductance state. Analysis of the open dwell-time also showed no significant differences in the
A

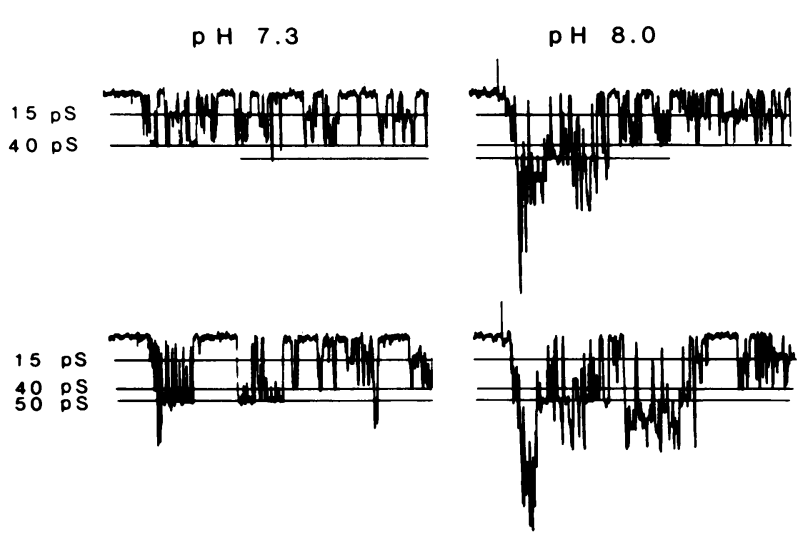

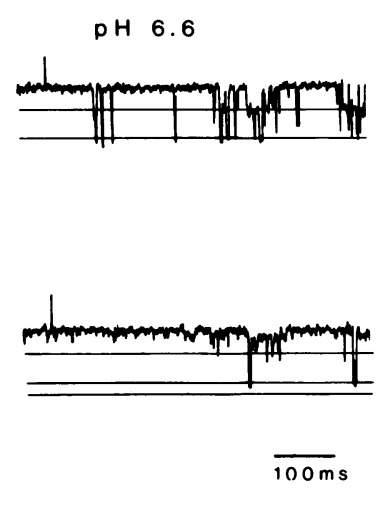

B

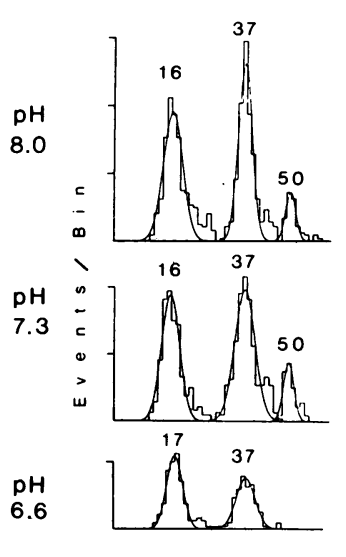

C

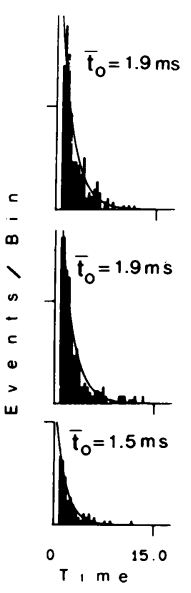

Fig. 5. Modulatory effect of $\mathrm{H}^{+}$in excised outside-out membrane patch. (A) One hundred micromolar NMDA and $1 \mu \mathrm{M}$ glycine were applied to a single excised outside-out patch in rapid step pulses of 400-msec duration. Ten step activations were recorded at 5-sec intervals for each $\mathrm{pH}$ in the order indicated. Not displayed are recordings when $\mathrm{pH}$ was returned to 7.3 , which was not significantly different from the initial recording at $\mathrm{pH} 7.3$. Holding potential was $-80 \mathrm{mV}$. $(B)$ Amplitude histograms from the same membrane patch shown in $A$. Distributions were fitted by Gaussian curves. The conductances calculated from the Gaussian fit are labeled over each distribution. Current amplitudes are plotted on the horizontal axis (bin widths are $0.1 \mathrm{pA}$ ); number of events per bin (axis mark represents 24 events per bin) is indicated on the vertical axis. The absolute number of opening events at $\mathrm{pH} 8.0$ is underrepresented due to overlapping openings that were rejected during analysis. Very low conductance openings were excluded from the histograms. $(C)$ Dwell-time histograms of the 37-pS conductance state. Distributions were fitted to a single exponential to determine mean dwell-time. Horizontal axis represents time in msec, vertical axis represents number of events per bin (axis mark represents 30 events per bin). 
dwell-time for the 37- and 50-pS openings between $\mathrm{pH} 8.0$ and 7.3 (Fig. 5C). Because binding of $\mathrm{H}^{+}$within the channel or close to the channel mouth would decrease either the unitary current or alter the probability of the channel being open, we concluded that the probable $\mathrm{H}^{+}$-binding site is not in close proximity to the channel permeation pathway.

\section{DISCUSSION}

Site and Mechanism of $\mathbf{H}^{+}$Modulation. Our results show that $\mathrm{H}^{+}$is a strong and relatively selective modulator of the NMDA channel over the physiological $\mathrm{pH}$ range. The mechanism for this modulation appears to be mediated primarily by alterations in the gating of the NMDA channel. Our data do not support either channel blockade or interference with agonist binding as possible alternative mechanisms for the $\mathrm{H}^{+}$-induced modulation of the NMDA response.

The first set of mechanisms (channel block), whereby ion permeation is directly hindered by $\mathrm{H}^{+}$, was studied by examining single-channel conductances and open dwelltimes. Three possibilities were considered: (i) If the protonation site was within the open-channel pore and the protonation-deprotonation reaction occurred on a time scale that could be resolved by the recording system, then a "flicker"type block in the single-channel recordings would be expected. An example of such a mechanism is the $\mathbf{M g}^{2+}$ block of the NMDA channel, where the channel conductance remains unchanged, but the open dwell-time is markedly shortened (5). (ii) If protonation was within the channel, but the reaction occurred on a time scale faster than could be resolved, a decrease in apparent unitary-channel conductance would be predicted. An example of this mechanism has been shown for $\mathrm{H}^{+}$block of the calcium channel in its sodium-conducting state (16). (iii) If protonation was outside the channel pore but close to the mouth of the channel where the positive charge could screen incoming ions, then one would also expect changes in the unitary channel conductance. We concluded that the protonation site is probably not close to the channel permeation pathway because no evidence for either a significant change in unitary channel conductances or for a "flicker"-type blockade by $\mathrm{H}^{+}$was found.

The second set of mechanisms (changing the affinity of the receptor) was studied by examining the interaction between $\mathrm{H}^{+}, \mathrm{NMDA}$, and glycine. If $\mathrm{H}^{+}$altered the affinity between the receptor and the agonist, the interaction would have been manifested as a competitive antagonism. The data (Fig. $2 B$ and $C$ ) show that the primary interactions between $\mathrm{H}^{+}$and NMDA and between $\mathrm{H}^{+}$and glycine were noncompetitive. The possibility that one part of the interaction between $\mathrm{H}^{+}$ and glycine may be competitive is not surprising. Autoradiographic studies of strychnine-insensitive glycine binding have shown similar $\mathrm{pH}$ dependence (17). Considering that the $\mathrm{pKa}$ for glycine protonation is at $\mathrm{pH} 2.34$ and 9.6 , it is improbable that the latter component of competitive interaction for glycine binding can be accounted for by change in the glycine ionization state. Despite evidence for a partial action on glycine binding, our data suggest that the dominant modulatory action of $\mathrm{H}^{+}$is not mediated by changes in the binding affinities of the receptor for either NMDA or glycine.

Other biologically important modulators that alter the gating of the NMDA channel by binding to a site external to the channel include glycine $(4)$ and $\mathrm{Zn}^{2+}(18,19)$. It is premature to speculate whether the modulatory actions of $\mathrm{H}^{+}$ may be expressed through a shared mechanism with one of these two modulators. However, we note with interest that $\mathrm{H}^{+}$shares with $\mathrm{Zn}^{2+}$ the preferential targeting of the higher conductance states of the NMDA channel (19); yet, the role of this preferential suppression in the overall modulation of the NMDA-activated current remains unclear.
Biological Role of Modulation. Changes in the concentration of $\mathrm{H}^{+}$have been clearly shown to serve important biological roles by regulating the properties of protein macromolecules (20). Within the nervous system, changes in intracellular $\left[\mathrm{H}^{+}\right]$modulate the gating of gap junction and potassium channels $(21,22)$ and are thought to play protective roles. We propose that the modulation of the NMDA channel by extracellular $\mathrm{H}^{+}$may also serve to protect neurons under hypoxic/ischemic conditions. A common pathway that may lead to irreversible neuronal injury is excessive calcium influx through either the voltage-gated calcium channels or the calcium-permeating NMDA channels (23). During hypoxic/ischemic injury to the brain, conditions for maximal NMDA channel activation are present. Measurements of $\mathrm{pH}$ within the extracellular space of the mammalian cortex reveal that $\mathrm{pH}$ falls to 6.5-6.6 within a minute of cardiac arrest (24). The dramatic acidification during ischemia may provide an important local feedback mechanism to limit calcium influx through the NMDA channel. The $\mathrm{pH}$ of the extracellular space may also shift in an alkaline direction with acute hyperventilation (25), a procedure routinely used to induce seizures in many epileptic patients (26). Furthermore, alkalosis-induced seizure activity can be blocked by the NMDA antagonist aminophosphonovaleric acid (AVP) (27). One explanation for these observations may be the potentiation of the NMDA response to alkalinization. The regulation of the NMDA receptor-channel complex by $\left[\mathrm{H}^{+}\right]_{0}$, therefore, has interesting implications in the research on treatment of stroke and seizures.

This work was supported by the Clinical Investigator Development Award (C.-M.T.), National Science Foundation Grant 24927 (M.D.), and National Institutes of Health Grant HL 16152 (M.M.).

1. Watkins, J. C. \& Evans, R. H. (1981) Annu. Rev. Pharmacol. Toxicol. 21, 16-204.

2. Mayer, M. L. \& Westbrook, G. L. (1987) Prog. Neurobiol. 28, 197-276.

3. MacDermott, A. B., Mayer, M. L., Westbrook, G. L., Smith, S. J. \& Barker, J. L. (1986) Nature (London) 321, 519-522.

4. Johnson, J. W. \& Ascher, P. (1987) Nature (London) 325, 529-531.

5. Nowak, L., Brogestovski, P., Ascher, P., Herbert, A. \& Prochiantz, A. (1984) Nature (London) 307, 462-465.

6. Mayer, M. L., Westbrook, G. L. \& Guthrie, P. B. (1984) Nature (London) 309, 261-263.

7. Collingridge, G. L. \& Bliss, T. V. P. (1987) Trends Neurosci. 10, 288-293.

8. Meldrum, B. S., Croucher, M. J., Badman, G. \& Collins, J. F. (1983) Neurosci. Lett. 39, 101-104.

9. Albers, G. W., Goldberg, M. P. \& Choi, D. W. (1989) Ann. Neurol. 25, 398-403.

10. Chesler, M. (1990) Prog. Neurobiol. 34, 401-427.

11. Tang, C., Dichter, M. \& Morad, M. (1989) Soc. Neurosci. Abstr. 15, 326.

12. Hamill, O. P., Marty, A., Neher, E., Sakmann, B. \& Sigworth, F. J. (1981) Pflügers Arch. 391, 85-100.

13. Grantyn, R. \& Lux, H. D. (1988) Neurosci. Lett. 89, 198-203.

14. Mayer, M. L., Vyklicky, L. \& Clements, J. (1989) Nature (London) 338, 425-427.

15. Jahr, C. E. \& Stevens, C. F. (1987) Nature (London) 325, 522-525.

16. Prod'hom, B., Pietrobon, D. \& Hess, P. (1987) Nature (London) 329, 243-246.

17. McDonald, J. W., Penney, J. B., Johnston, M. V. \& Young, A. B. (1990) Neuronscience 35, 653-668.

18. Christine, C. W. \& Choi, D. W. (1990) J. Neurosci. 10, 108 116.

19. Westbrook, G. L. \& Legendre, P. (1989) Soc. Neurosci. Abstr. $15,828$.

20. Stryer, L. (1988) Biochemistry (Freeman, New York).

21. Spray, D. C., Harris, A. L. \& Bennett, M. V. L. (1981) Science 211, 712-715. 
22. Byerly, L. \& Moody, W. J. (1986) J. Physiol. (London) 376, $477-491$.

23. Cheung, J. Y., Bonventre, J. V., Malis, C. D. \& Leaf, A. (1986) N. Engl. J. Med. 314, 1670-1676.

24. Siesjo, B. K., Hanwehr, R., Nergelius, G., Nevander, G. \& Ingvar, M. (1985) J. Cerebo Blood Flow Metab. 5, 47-57.
25. Balestrino, M. \& Somjen, G. G. (1988) J. Physiol. (London) 396, 247-266.

26. Adams, R. D. \& Victor, M. (1989) Principles of Neurology (McGraw-Hill, New York), 4th Ed., p. 251.

27. Aram, J. A. \& Lodge, D. (1987) Neurosci. Lett. 83, 345350. 